\title{
The Clinical Features and Risk Factors of Parenchymal Neuro-Behcet's Disease
}

\author{
Dong Yan, ${ }^{1,2}$ JinJing Liu, ${ }^{1}$ Yuehua Zhang, ${ }^{3}$ Wei Yuan, ${ }^{4}$ Yan Xu, ${ }^{5}$ Jing Shi, ${ }^{1}$ Chaoran Li, \\ Yining Wang, ${ }^{6}$ Linyi Peng, ${ }^{1}$ Yunjiao Yang, ${ }^{1}$ Jiaxin Zhou, ${ }^{1}$ Di Wu, ${ }^{1}$ Zhichun Liu, ${ }^{2}$ \\ Xiaofeng Zeng, ${ }^{1}$ Fengchun Zhang, ${ }^{1}$ Wenjie Zheng $\mathbb{D}^{1}{ }^{1}$ and Yan Zhao $\mathbb{D}^{1}$ \\ ${ }^{1}$ Department of Rheumatology and Clinical Immunology, Peking Union Medical College Hospital, Clinical Immunology Center, \\ Chinese Academy of Medical Sciences and Peking Union Medical College, the Ministry of Education Key Laboratory, \\ Beijing 100730, China \\ ${ }^{2}$ Department of Rheumatology and Immunology, The Second Affiliated Hospital of Soochow University, Suzhou 215004, China \\ ${ }^{3}$ Department of Oncology and Immunology, The Fourth Hospital of Hebei Medical University, Shijiazhuang 050011, China \\ ${ }^{4}$ Department of Rheumatology, Kailuan General Hospital, Hebei United University, Tangshan 063000, China \\ ${ }^{5}$ Department of Neurology, Peking Union Medical College Hospital, Beijing 100730, China \\ ${ }^{6}$ Department of Radiology, Peking Union Medical College Hospital, Beijing 100730, China
}

Correspondence should be addressed to Wenjie Zheng; wenjzheng@gmail.com and Yan Zhao; zhaoyan_pumch2002@aliyun.com

Received 8 December 2018; Revised 3 July 2019; Accepted 20 July 2019; Published 12 September 2019

Academic Editor: Eirini Rigopoulou

Copyright (c) 2019 Dong Yan et al. This is an open access article distributed under the Creative Commons Attribution License, which permits unrestricted use, distribution, and reproduction in any medium, provided the original work is properly cited.

\begin{abstract}
To investigate the clinical features of parenchymal neuro-Behcet's disease (p-NBD), we retrospectively reviewed the medical records of 1009 BD patients admitted to Peking Union Medical College Hospital from 2000 to 2016. Forty-two patients (25 males and 17 females) with p-NBD and eighty-four age- and sex-matched BD patients without neurological involvement who were served as controls were enrolled. Neurological onset was concomitant with the onset of BD in six cases (14.3\%). Pyramidal signs $(50.0 \%)$ and headache $(33.3 \%)$ were the most common manifestations. On MRI, the lesions were mainly in the midline structures and hyperintense in the T2-weighted image. The most common lesion was the brainstem (54.8\%). Spinal cord involvement was observed in five cases, four of which with cervical cord involvement. Multifocal lesions were observed in 13 patients. Ocular involvement was more prevalent in p-NBD $(35.7 \%)(P=0.041, \mathrm{OR}=2.36,95 \% \mathrm{CI}=1.03-5.44)$ compared with controls. All patients received corticosteroids and immunosuppressants, mainly cyclophosphamide (39/42). Six patients with severe/refractory condition received biological agents and achieved response measured by decreased Rankin score $(P=0.002)$. With a median follow-up of 28 months, 22 patients (61.1\%) achieved clinical improvements, while 10 (27.8\%) relapsed and 4 died (mortality rate 11.1\%). p-NBD is a rare yet disabling and life-threatening complication of BD. Ocular involvement is a risk factor for p-NBD. Promptly aggressive treatment is essential for improving prognosis, and biological agents might be a promising approach for severe/refractory $\mathrm{p}-\mathrm{NBD}$.
\end{abstract}

\section{Introduction}

Behcet's disease (BD) is a multisystem inflammatory disease with unknown etiology. Central nervous system involvement in $\mathrm{BD}$, the so-called neuro-Behcet's disease (NBD), is one of its most serious complications and an important cause of morbidity and mortality [1]. The frequency of NBD greatly varies from $1.3 \%$ [2] to 59\% [3], due to differences in ethnic, geographical distribution, and study designs. It can be caused by either primary neural parenchymal lesions or secondary to vascular involvement. The former is called parenchymal NBD (p-NBD) and represents the majority of NBD [4-6]. According to the site of the lesions, p-NBD can be classified as multifocal/diffuse, brainstem, spinal cord, cerebral, asymptomatic, and optic neuropathy [7]. It may present with numerous manifestations, such as pyramidal signs, headache, and dysarthria, consistent with the site of the lesions. The 10year mortality of p-NBD is $10 \%$ [7], while nonparenchymal 
NBD (non-p-NBD) often tends to recover well with appropriate and prompt treatment.

To date, p-NBD has been reported in some other countries $[4,8-12]$ and the clinical features of Chinese p-NBD patients have not been characterized by clarity. To address this issue, we conducted a retrospective study on hospitalized $\mathrm{BD}$ patients and identified the patients with p-NBD. We summarized the clinical characteristics, the cerebrospinal fluid (CSF) tests, magnetic resonance imaging (MRI) findings, treatment, and prognosis and further explored the potential risk factors for $\mathrm{p}-\mathrm{NBD}$ in order to make an early diagnosis and improve prognosis.

\section{Materials and Methods}

2.1. Patients. BD patients who were admitted to Peking Union Medical College Hospital from 2000 to 2016 were retrospectively enrolled. All patients fulfilled 1990 International Study Group (ISG) BD criteria [13] or new International Criteria for BD (ICBD) [14]. The diagnosis of neurological involvement was based on the abnormalities on neurological examination, CSF analysis, or neuroradiological examinations. The diagnosis was made by two rheumatology experts and two neurology experts according to the criteria of the 2014 International Consensus on NBD [15]. We chose the modified Rankin score to assess the disability status of NBD patients [16]. Clinical data including demographics, clinical features, laboratory tests, imaging, treatment, and outcome were retrospectively extracted from the medical records.

The courses of $\mathrm{p}-\mathrm{NBD}$ were classified as the acute course (defined as acute onset of neurological symptoms and signs lasting $>24$ hours), chronic progressive course, and silent course (defined as detection of abnormal findings on neurological examination in cases who did not have any neurological complaints) [11].

We randomly matched eighty-four BD patients (at $1: 2$ ratio) without neurological involvement by sex and age as the control group to identify the risk factors in $\mathrm{p}-\mathrm{NBD}$. The study was reviewed and approved by the institutional ethics review board of Peking Union Medical College Hospital in accordance with the Declaration of Helsinki. Given the study was based on the review of medical records, written informed consent was waived. The patient's records/information was anonymized and deidentified prior to the analysis.

2.2. Statistical Analysis. Statistical analysis was performed with SPSS version 21.0 (IBM Inc., Armonk, USA). Frequencies and percentages were used for categorical variables. Mean \pm standard deviation (SD) was used to express quantitative variables of the normal distribution, while median and range were used for abnormal distribution. The continuous variables were analyzed by $t$-test or Mann-Whitney $U$ test, as appropriate. A value of $P<0.05$ was regarded as indicating statistical significance.

\section{Result}

3.1. Epidemiology. Of 1009 hospitalized BD patients in the same academic hospital during the same period, NBD was
TABLE 1: Clinical manifestations of BD.

\begin{tabular}{lc}
\hline Clinical manifestations & $N(\%)$ \\
\hline Oral ulcers & $42(100 \%)$ \\
Genital ulcers & $27(64.3 \%)$ \\
Skin lesions & $19(45.2 \%)$ \\
Ocular involvement & $15(35.7 \%)$ \\
Arthritis & $9(21.4 \%)$ \\
Vascular involvement & $6(14.3 \%)$ \\
Gastrointestinal lesions & $3(7.1 \%)$ \\
\hline
\end{tabular}

documented in 62 patients (6.1\%), and a total of 42 patients had parenchymal involvement $(4.2 \%, 25$ males and 17 females). In patients with $\mathrm{p}-\mathrm{NBD}$, the male/female ratio was $1.47: 1$. Their age at onset of $\mathrm{BD}$ was $30.0 \pm 11.1$ years old, and age at neurological onset was $35.3 \pm 12.1$ years old. Most of the patients suffered neurological symptoms after other initial systemic symptoms of BD in the median interval of 2 months (range from 0 to 18 months). Neurological onset was concomitant with the onset of BD in six cases (14.3\%). Additionally, of the $20 \mathrm{NBD}$ patients but without p-NBD in our cohort, 17 patients were presented with cerebral venous sinus thrombosis (CVST) and the other three patients had peripheral nervous system involvement.

3.2. BD Manifestations. In patients with $\mathrm{p}-\mathrm{NBD}$, oral ulceration presented in all, followed by genital ulcers $(64.3 \%)$, skin lesions (45.2\%) (including pseudofolliculitis, erythema nodosa, or positive pathergy test), ocular involvement (35.7\%) (including uveitis, retinal vasculitis, and scleritis), arthritis (21.4\%), vascular involvement (14.3\%) (deep vein thrombosis in 5 cases and pulmonary embolism in 1 case), and gastrointestinal involvement (7.1\%) (all presented as terminal ileum ulceration). Only one case had mitral valve lesion (Table 1).

\section{Neurological Features}

4.1. Clinical Features. Seventeen patients (40.5\%) presented with an acute onset and 24 patients (57.1\%) had a progressive course, while one case showed a silent course. The most common involved sites of p-NBD were brainstem (23/42, 54.8\%) and hemisphere $(22 / 42,52.4 \%)$. Five cases (11.9\%) had spinal cord involvement, in which 4 had cervical cord involved and one had thoracic cord involved. 13 cases (31.0\%) suffered from multiple lesions (Table 2). The diagnosis of $\mathrm{p}-\mathrm{NBD}$ in 3 cases was based on the typical neurological symptoms and signs, abnormal CSF examinations, and electroencephalogram, though neuroradiological findings were normal. In addition to $\mathrm{BD}$, no other diagnosis could better explain the clinical picture.

Patients with $\mathrm{p}$-NBD had a variety of neurological signs and symptoms (Table 3 ). The most common clinical symptoms were pyramidal signs $(50.0 \%)$, followed by headache and psychological and behavioral change (each 33.3\%). Irritating cough (31\%), myasthenia (28.6\%), dysarthria $(26.2 \%)$, and movement disorder (21.4\%) were also commonly 
TABLE 2: Sites of neurological involvement in p-NBD.

\begin{tabular}{lc}
\hline Neurological lesions & $N(\%)$ \\
\hline Brainstem involvement & $23(54.8 \%)$ \\
Isolated brainstem & $10(23.8 \%)$ \\
Brainstem+ & $13(31.0 \%)$ \\
Hemicerebrum involvement & $22(52.4 \%)$ \\
Spinal cord involvement & $5(11.9 \%)$ \\
Cervical cord & $4(9.5 \%)$ \\
Thoracic cord & $1(2.4 \%)$ \\
Cerebellum & $4(9.5 \%)$ \\
Localization not possible & $3(7.1 \%)$ \\
More than two sites & $13(31.0 \%)$ \\
\hline
\end{tabular}

*These 3 patients showed only neurological clinical symptoms and abnormal CSF examinations, and in all these 3 cases, MRI was normal.

TABLE 3: Clinical manifestations of p-NBD.

\begin{tabular}{lc}
\hline Neurological symptoms & $N(\%)$ \\
\hline Pyramidal sign & $21(50.0 \%)$ \\
Headache & $14(33.3 \%)$ \\
Psychological and behavioral change & $14(33.3 \%)$ \\
Irritating cough & $13(31.0 \%)$ \\
Myasthenia & $12(28.6 \%)$ \\
Dysarthria & $11(26.2 \%)$ \\
Movement disorder & $9(21.4 \%)$ \\
Urinary retention & $7(16.7 \%)$ \\
Visual loss & $6(14.3 \%)$ \\
Cognitive dysfunction & $5(11.9 \%)$ \\
Epilepsy & $4(9.5 \%)$ \\
Conscious disturbance & $4(9.5 \%)$ \\
Ataxia & $4(9.5 \%)$ \\
Hemiplegia & $3(7.1 \%)$ \\
\hline
\end{tabular}

observed. Some symptoms were less frequently noticed such as urinary retention, visual loss, cognitive dysfunction, epilepsy, conscious disturbance, ataxia, and hemiplegia.

4.2. Neurological Imaging. All patients received neurological MRI examination. Thirty-nine cases presented with parenchymal lesions. Of those with parenchymal impairment, the brainstem, the periventricular area, the centrum semiovale, and the spinal cord were involved in twenty-two (22/42), thirteen (13/42), eight (8/42), and five patients (5/42), respectively. Typically, the lesions were hyperintense on T2-weighted MRI and hypointense on T1-weighted sequences. Only one patient had brainstem atrophy, whose interleukin-6 (IL-6) level in CSF was elevated (78.5 pg/mL).

4.3. CSF Analysis. CSF analysis was performed in 40 patients. The opening pressure was increased in 8 cases $(20 \%)$, ranging from 195 to $270 \mathrm{mmH}_{2} \mathrm{O}$. CSF protein was mildly elevated in 22 cases, with a mean level of $0.51 \pm 0.24 \mathrm{~g} / \mathrm{L}$. All cases showed normal chloride and glucose level of CSF. Pleocytosis was shown in 11 cases, and assessment of cytological exami- nation of CSF was conducted in 20 patients. Nine cases showed mixed pictures with lymphocyte predominance, and two cases showed mainly neutrophil picture. Both CSF and serum protein electrophoresis for oligoclonal bands (OCB) were performed in 21 cases. Seven cases were positive in CSF while negative in serum (33.3\%). CSF cytokine levels were tested in three cases during acute attacks. Elevated IL-6 and tumor necrosis factor (TNF- $\alpha$ ) levels were detected in two patients, respectively.

4.4. Laboratory Examinations. Erythrocyte sedimentation rate (ESR) was significantly elevated in $45.2 \%(19 / 42)$ with the median level of 15 (ranged $0-85 \mathrm{~mm} / \mathrm{h}$ ). While hypersensitive C-reactive protein (hs-CRP) levels elevated in 50\% $(21 / 42)$ with the median level of $3.0(0.14-124 \mathrm{mg} / \mathrm{L})$. All patients but one showed low-titer antinuclear antibody (ANA) $(1: 160)$.

4.5. Comparison between Acute and Progressive p-NBD. The data showed no statistical significance in clinical features, sites of neurological involvement, CSF tests, and laboratory examinations between acute and progressive $\mathrm{p}-\mathrm{NBD}$ patients $(P>0.05)$ (data not shown).

4.6. Comparison with $B D$ without Neurological Involvement. Eighty-four age- and gender-matched BD patients without neurological involvement were randomly selected at $1: 2$ ratio and served as the control group. Compared with the controls, the prevalence of ocular involvement (including uveitis, retinal vasculitis, and scleritis) was significantly higher in $\mathrm{p}-\mathrm{NBD}(35.7 \%)(P=0.041, \mathrm{OR}=2.36,95 \% \mathrm{CI}=$ 1.03-5.44) (Table 4). The average interval from the onset of ocular to neurological symptoms was $42.7 \pm 38.1$ months. Fifteen cases had ocular involvement, among whom six cases were treated with cyclosporine A (CsA) before the onset of neurological symptoms with the dosage ranging from $75 \mathrm{mg}$ bid to $150 \mathrm{mg}$ bid for $(36.2 \pm 36.1)$ months. Some other clinical manifestations, ESR, and CRP showed no statistical significance.

4.7. Treatment and Outcome. All p-NBD patients received corticosteroids (as prednisone $\geq 1 \mathrm{mg} / \mathrm{kg} / \mathrm{d}$ or the equivalent dosage of other corticosteroids) and 23 patients (54.8\%) received methylprednisolone pulse therapy. A total of forty patients were treated with immunosuppressants, in which cyclophosphamide (CTX) 39 cases, CsA 4 cases, azathioprine (AZA) 3 cases, methotrexate (MTX) 1 case, and thalidomide 1 case. Nine patients received more than one immunosuppressant. Intrathecal injection of dexamethasone $10 \mathrm{mg}$ and methotrexate $10 \mathrm{mg}$ was administrated in 28 patients.

Six severe and/or refractory p-NBD patients, with a poor baseline disability status (mean Rankin score was 4), received biological agents, including infliximab (IFX) in 4 cases, tocilizumab (TCZ) in 1 case, and interferon (IFN)- $\alpha 2 \mathrm{a}$ in 1 case (Table 5). After a median follow-up of 21.5 months, all the patients achieved clinical improvements. The Rankin score was significantly decreased to $(2.2 \pm 0.8)(P=0.002)$. Additionally, follow-up MRI showed the lesions significantly reduced in two of them. Furthermore, the dosage of corticosteroids was tapered from prednisone $\geq 1 \mathrm{mg} / \mathrm{kg} / \mathrm{d}$ to 0 - 
TABLE 4: Clinical comparison of p-NBD and BD without neurological involvement*.

\begin{tabular}{|c|c|c|c|c|}
\hline Parameters & $\mathrm{p}-\mathrm{NBD}(n=42)$ & Controls $^{¥}(n=84)$ & $P$ value & OR $(95 \% \mathrm{CI})$ \\
\hline Age (years, mean $\pm S D$ ) & $36.3 \pm 11.6$ & $35.2 \pm 10.9$ & 0.601 & $1.01(0.98-1.04)$ \\
\hline Gender (F/M) & $25 / 17$ & $50 / 34$ & 1.000 & - \\
\hline \multicolumn{5}{|l|}{ Clinical features of $\mathrm{BD}$} \\
\hline Oral ulceration & $42(100 \%)$ & $84(100 \%)$ & 1.000 & - \\
\hline Genital ulceration & $27(64.3 \%)$ & $61(72.6 \%)$ & 0.337 & $0.68(0.31-1.50)$ \\
\hline Skin lesions & $19(45.2 \%)$ & $40(47.6 \%)$ & 0.801 & $0.91(0.43-1.91)$ \\
\hline Gastrointestinal lesions & $3(7.1 \%)$ & $17(20.2 \%)$ & 0.058 & $0.30(0.08-1.10)$ \\
\hline Ocular involvement & $15(35.7 \%)$ & $16(19.0 \%)$ & $0.041^{\|}$ & $2.36(1.03-5.44)$ \\
\hline Vascular involvement & $6(14.3 \%)$ & $10(11.9 \%)$ & 0.705 & $1.23(0.42-3.66)$ \\
\hline \multicolumn{5}{|l|}{ Laboratory tests } \\
\hline $\mathrm{ESR}(\mathrm{mm} / \mathrm{h}$, median and range $)$ & $15(0-85)$ & $11(1-80)$ & 0.072 & $1.01(0.99-1.03)$ \\
\hline CRP (mg/L, median and range) & $3.0(0.14-124)$ & $3.3(0.13-104)$ & 0.995 & $1.00(0.98-1.02)$ \\
\hline
\end{tabular}

$\mathrm{OR}=$ odds ratio; $\mathrm{CI}=$ confidential interval. ${ }^{*}$ Values are the number (percentage) unless otherwise indicated. ${ }^{*}$ Eighty-four age- and gender-matched $\mathrm{BD}$ patients without neurological involvement were served as control. Ocular involvement includes uveitis, retinal vasculitis, and scleritis. ${ }^{\|} P<0.05$.

$10 \mathrm{mg} / \mathrm{d}$, and immunosuppressants were tapered in number and dosage in $3(50 \%)$ and 6 patients (100\%), respectively. No serious adverse events were observed.

Overall, with a median follow-up of 28 months (4 to 156 months), 22 out of 36 patients $(61.1 \%)$ achieved clinical improvements, including the four patients treated with CsA after the diagnosis of p-NBD. 10 patients (27.8\%) relapsed and 4 patients died (the mortality rate was $11.1 \%$ ). Six patients were lost to follow-up.

\section{Discussion}

p-NBD accounted for $67.7 \%$ of neuro-Behcet's disease in our cohort, and the proportion and the male predominance $(59.5 \%)$ was similar to the data reported $[11,12,17]$. The neurological symptoms usually occur after the BD diagnosis is established. However, in 6 patients (14.3\%), the neurological manifestations preceded the diagnosis of $\mathrm{BD}$ in our series. This emphasizes that rheumatologists and neurologists must be aware of this possible rare cause of neurological symptoms.

As previously reported, the most frequently affected area of p-NBD was the brainstem [4]. Hemicerebrum, spinal cord, and cerebellum can also be involved. Nearly one-third of the patients suffered from multiple lesions. In our study, cervical cord involvement was more common in spinal cord lesions, while previous research has shown that thoracic cord was more susceptible [18]. The difference may be due to different race or study design. The most common initial manifestations of $\mathrm{p}-\mathrm{NBD}$ were pyramidal signs and headaches, as described in the literature [7]. Psychological and behavioral change showed a high incidence in our study. Atypical symptoms may lead to misdiagnosis.

CSF examination plays an important role in the diagnosis of $\mathrm{p}-\mathrm{NBD}$. Our data suggested that most $\mathrm{p}-\mathrm{NBD}$ patients tend to have normal intracranial pressure and CSF pleocytosis. The pleocytosis pictures of CSF can present as neutrophil-predominant or lymphocyte-predominant depending on the course of the disease [7]. Our data showed a higher CSF-OCB-positive rate in $\mathrm{p}-\mathrm{NBD}$ than the previous reports $[8,11]$. All these CSF-OCB-positive cases in our cohort were in an acute course and with high disease activity. As a previous study showed CSF oligoclonal IgA and IgM may be helpful in monitoring CNS disease activity in NBD [19]. A further study to monitor CSF-OCB in both active and remission periods of $\mathrm{p}-\mathrm{NBD}$ would be more valuable. Two cases showed high-level proinflammatory cytokines in accordance with active disease. Proinflammatory cytokines such as IL-6 can be markers of disease activity or prognosis [20].

MRI has obvious advantages in displaying small vessel lesions. The most commonly affected site was the midline structure, such as the brainstem. Most lesions in p-NBD were hyperintense on T2-weighted MRI. The previous study indicated that brainstem atrophy, especially in the absence of cortical atrophy, is highly specific to the diagnosis of NBD [21]. Meanwhile, high levels of proinflammatory cytokines, especially IL-6, might be important for the induction of apoptosis of neurons in p-NBD [22]. In our study, one case showed brainstem atrophy on MRI with high-level CSF-IL-6. Given the complexity of the disease, the measurement of a single cytokine does not provide sufficient discrimination to assess the correlation of imaging changes and disease courses [23].

Our data revealed a high frequency of ocular involvement in p-NBD. Ocular involvement, like uveitis, retinitis, and scleritis, is a "warning sign" for predisposition to parenchymal involvement in BD. The recent study from Turkey [9] also showed the significant association between posterior uveitis and $\mathrm{p}-\mathrm{NBD}$. The mechanism of this phenomenon has not been clarified. A meta-analysis showed that the risk of developing nervous system involvement was significantly higher among BD patients who used CsA compared with those who did not $(\mathrm{RR}=8.26,95 \% \mathrm{CI}=4.45-15.32)$ [24]. In our cohort, six cases complicated with ocular involvement treated with CsA before the onset of p-NBD and the immunosuppressants were adjusted after the neurological attack. However, four cases received high-dose methylprednisolone pulse therapy followed by oral prednisone plus CsA after 
TABLE 5: Biological agents in 6 severe/refractory p-NBD cases.

(a)

\begin{tabular}{|c|c|c|c|c|c|c|}
\hline \multirow{2}{*}{ Case } & \multirow{2}{*}{ Age } & \multirow{2}{*}{$\mathrm{M} / \mathrm{F}$} & \multirow{2}{*}{$\begin{array}{l}\text { History of } \\
\text { treatment }\end{array}$} & \multicolumn{3}{|c|}{ Clinical manifestations of p-NBD } \\
\hline & & & & Symptoms & Lesion sites & CSF tests \\
\hline 1 & 24 & $\mathrm{M}$ & $\mathrm{GC}^{\mathrm{a}} \mathrm{CTX}$ & $\begin{array}{l}\text { Pyramidal sign, ataxia, } \\
\text { irritating cough }\end{array}$ & $\begin{array}{c}\text { Brainstem, cerebellum, } \\
\text { spinal cord }\end{array}$ & Normal \\
\hline 2 & 45 & $\mathrm{M}$ & GC $^{\mathrm{a}}$ CTX THD & $\begin{array}{l}\text { Pyramidal sign, dysarthria, } \\
\text { irritating cough }\end{array}$ & Brainstem, cerebellum & $\begin{array}{c}\text { Pro } 0.46 \mathrm{~g} / \mathrm{L}, \text { normal pressure, } \\
\text { and cytological test }\end{array}$ \\
\hline 3 & 35 & $\mathrm{M}$ & $\mathrm{GC}^{\mathrm{a}} \mathrm{CTX}$ & $\begin{array}{l}\text { Pyramidal sign, epilepsy, } \\
\text { psychological and behavioral } \\
\text { change, disturbance } \\
\text { of urine, myasthenia }\end{array}$ & $\begin{array}{l}\text { Brainstem, hemicerebrum, } \\
\text { spinal cord }\end{array}$ & $\begin{array}{c}\mathrm{ICP} 200 \mathrm{mmH}_{2} \mathrm{O} \\
\text { WBC } 37 * 10^{6} / \mathrm{L} \text {, Pro } 1.19 \mathrm{~g} / \mathrm{L}\end{array}$ \\
\hline 4 & 15 & $\mathrm{M}$ & $\mathrm{GC}^{\mathrm{b}} \mathrm{MTX}$ & Epilepsy, headache & Not possible & $\begin{array}{c}\text { ICP } 235 \mathrm{mmH}_{2} \mathrm{O} \text {, normal } \\
\text { biochemical and cytological test }\end{array}$ \\
\hline 5 & 36 & $\mathrm{M}$ & GC $^{\mathrm{b}}$ MTX AZA & $\begin{array}{l}\text { Psychological and behavioral } \\
\text { change, disturbance of } \\
\text { urine, myasthenia }\end{array}$ & $\begin{array}{l}\text { Brainstem, hemicerebrum, } \\
\text { spinal cord }\end{array}$ & WBC $70 * 10^{6} / \mathrm{L}$, Pro $0.61 \mathrm{~g} / \mathrm{L}$ \\
\hline 6 & 15 & $\mathrm{~F}$ & GC $^{\mathrm{a}}$ CTX CsA & $\begin{array}{l}\text { Dysarthria, irritating } \\
\text { cough, psychological and } \\
\text { behavioral change }\end{array}$ & Hemicerebrum & $\begin{array}{c}\text { ICP } 246 \mathrm{mmH}_{2} \mathrm{O} \text {, normal } \\
\text { biochemical and cytological test }\end{array}$ \\
\hline
\end{tabular}

(b)

\begin{tabular}{|c|c|c|c|c|c|c|c|}
\hline \multirow{2}{*}{ Case } & \multicolumn{4}{|c|}{ Treatment of biological agents } & \multicolumn{3}{|c|}{ Follow-up } \\
\hline & Biological agents & Dose & Course & Drug combination & Symptoms & Side effects & Period (months) \\
\hline 1 & IFX & $3 \mathrm{mg} / \mathrm{kg}$ & 4 times & $\mathrm{GC}^{\mathrm{c}} \mathrm{CTX}$ & Improved & None & 31 \\
\hline 2 & IFX & $5 \mathrm{mg} / \mathrm{kg}$ & 5 times & $\mathrm{GC}^{\mathrm{c}} \mathrm{CTX}$ & $\begin{array}{c}\text { Improved and ESR/CRP } \\
\text { became normal }\end{array}$ & None & 12 \\
\hline 3 & IFX & $3 \mathrm{mg} / \mathrm{kg}$ & 4 times & $\mathrm{GC}^{\mathrm{c}} \mathrm{AZA}$ & $\begin{array}{l}\text { Symptoms and follow-up } \\
\text { MRI got improved }\end{array}$ & None & 9 \\
\hline 4 & IFX & $3 \mathrm{mg} / \mathrm{kg}$ & 5 times & MTX & No more seizures & None & 72 \\
\hline 5 & TCZ & $8 \mathrm{mg} / \mathrm{kg}$ & 10 times & $\mathrm{GC}^{\mathrm{c}} \mathrm{AZA}$ & $\begin{array}{l}\text { Symptoms and follow-up } \\
\text { MRI got improved }\end{array}$ & None & 11 \\
\hline 6 & IFN- $\alpha 2 \mathrm{a}$ & $3 \mathrm{Mu}$ & 53 months & $\mathrm{GC}^{\mathrm{c}} \mathrm{CsA}$ & $\begin{array}{c}\text { Improved and ESR/CRP } \\
\text { became normal }\end{array}$ & None & 104 \\
\hline
\end{tabular}

GC: glucocorticoid; CTX: cyclophosphamide; THD: thalidomide; MTX: methotrexate; AZA: azathioprine; CsA: cyclosporine A; Pro: protein; ICP: intracranial pressure; WBC: white blood cell. ${ }^{\mathrm{a}}$ Methylprednisolone pulse therapy. ${ }^{\mathrm{b}}$ As prednisone $\geq 1 \mathrm{mg} / \mathrm{kg} / \mathrm{d}$ or the equivalent dosage of other corticosteroids. ${ }^{\mathrm{c}} \mathrm{As}$ prednisone $5 \mathrm{mg} / \mathrm{d}-10 \mathrm{mg} / \mathrm{d}$.

the diagnosis of $\mathrm{p}-\mathrm{NBD}$, achieved remission, and remained stable during the follow-up.

Glucocorticoids and immunosuppressants are the cornerstones for the management of p-NBD [25]. However, no treatment option for $\mathrm{p}-\mathrm{NBD}$ has been supported by randomized trials. CTX was the most commonly used immunosuppressant in our study, and some cases required combination therapy with multiple immunosuppressants. Systemic administration combined with intrathecal injection with MTX and/or dexamethasone was also effective. For the severe and/or refractory $\mathrm{p}$-NBD cases, biological therapy achieved clinical and imaging improvement in addition to successfully tapering immunosuppressants, indicating a potential steroid- and immunosuppressant-sparing effect. Recently, there is growing evidence revealing the efficacy of the biological agents, such as TNF- $\alpha$ inhibitors [26], TCZ [27], and IL-1 inhibitor [28], suggesting alternative therapeu- tic approaches for refractory cases. The international consensus [15] and 2018 EULAR recommendations [25] for p-NBD also recommended anti-TNF therapy to be considered on severe disease as first-line or refractory patients. We assume that earlier and more widespread use of biologics may improve the outcome. We expect more clinical research to confirm this opinion in the future.

In concordance with previous reports, our study showed a poor prognosis in $\mathrm{p}-\mathrm{NBD}$. Four patients died from the disease. Early recognition of severe organ involvements is essential for improving prognosis.

Our study presents the clinical characteristics of the largest cohort of Chinese patients over 16 years. It has several limitations. Firstly, since all patients were enrolled from a national referral center, a potential selection bias toward severe cases could not be excluded. Secondly, it was a retrospective study. Given the limited number of cases, we could 
not clarify the correlation between CsA and the pathogenesis of NBD. A further multicenter case-control study is warranted to overcome these limitations.

\section{Conclusions}

In summary, the parenchymal neurological involvement is a rare complication of $\mathrm{BD}$ with a high morbidity and mortality. It has a male predominance and most commonly involves the brainstem. Ocular involvement is a risk factor for $\mathrm{p}-\mathrm{NBD}$. Glucocorticoids and immunosuppressants are the major therapies. Although larger studies are still needed to clarify some issues, as safety and sustained response after discontinuation, biological agents may be a useful alternative choice for $\mathrm{p}-\mathrm{NBD}$ patients with severe organ damage or refractory to conventional therapy.

\section{Data Availability}

The data used to support the findings of this study are included within the article.

\section{Conflicts of Interest}

The authors declare that there is no conflict of interest regarding the publication of this paper.

\section{Authors' Contributions}

Dong Yan, JinJing Liu, and Yuehua Zhang contributed equally to this work.

\section{Acknowledgments}

We gratefully acknowledge all patients who participated in our study. This work was supported by the National Natural Science Foundation of China (grant numbers 81571598 and 81871299); the National Key Research and Development Program: "Precise Medical Research" (grant number 2016YFC0906201); the CAMS Initiative for Innovative Medicine (grant number 2016-I2M-1013); the Chinese Academy of Medical Sciences Innovation Fund for Medical Sciences (CIFMS2017-I2M-1-008); and the Chinese National Key Technology R\&D Program, Ministry of Science and Technology (2017YFC0907601 and 2017YFC0907605).

\section{References}

[1] E. Kural-Seyahi, I. Fresko, N. Seyahi et al., "The long-term mortality and morbidity of Behçet syndrome: a 2-decade outcome survey of 387 patients followed at a dedicated center," Medicine, vol. 82, no. 1, pp. 60-76, 2003.

[2] U. Tursen, A. Gurler, and A. Boyvat, "Evaluation of clinical findings according to sex in 2313 Turkish patients with Behcet's disease," International Journal of Dermatology, vol. 42, no. 5, pp. 346-351, 2003.

[3] S. Farah, A. al-Shubaili, A. Montaser et al., "Behçet's syndrome: a report of 41 patients with emphasis on neurological manifestations," Journal of Neurology, Neurosurgery, \& Psychiatry, vol. 64, no. 3, pp. 382-384, 1998.
[4] M. H. Houman, S. Bellakhal, T. B. Salem et al., "Characteristics of neurological manifestations of Behçet's disease: a retrospective monocentric study in Tunisia," Clinical Neurology and Neurosurgery, vol. 115, no. 10, pp. 2015-2018, 2013.

[5] D. L. Yoon, Y. J. Kim, B. S. Koo, Y. G. Kim, C. K. Lee, and B. Yoo, "Neuro-Behçet's disease in South Korea: clinical characteristics and treatment response," International Journal of Rheumatic Diseases, vol. 17, no. 4, pp. 453-458, 2014.

[6] A. Riera-Mestre, S. Martínez-Yelamos, A. Martínez-Yelamos, I. Ferrer, R. Pujol, and A. Vidaller, "Clinicopathologic features and outcomes of neuro-Behçet disease in Spain: a study of 20 patients," European Journal of Internal Medicine, vol. 21, no. 6, pp. 536-541, 2010.

[7] A. Al-Araji and D. P. Kidd, "Neuro-Behçet's disease: epidemiology, clinical characteristics, and management," The Lancet Neurology, vol. 8, no. 2, pp. 192-204, 2009.

[8] S. Daoudi, M. Lounis, and M. Ait-Kaci-Ahmed, "Parenchymal neuro-Behcet's disease. Clinical and paraclinical characteristics, a report of 40 cases," La Presse Médicale, vol. 43, no. 5, pp. e119-e125, 2014.

[9] B. Bitik, A. Tufan, K. Sahin et al., "The association between the parenchymal neurological involvement and posterior uveitis in Behçet's syndrome," Clinical and Experimental Rheumatology, vol. 34, Supplement 102, pp. 82-85, 2016.

[10] E. Shugaiv, E. Tüzün, M. Mutlu, A. Kiyat-Atamer, M. Kurtuncu, and G. Akman-Demir, "Mycophenolate mofetil as a novel immunosuppressant in the treatment of neuroBehçet's disease with parenchymal involvement: presentation of four cases," Clinical and Experimental Rheumatology, vol. 29, Supplement 67, pp. S64-S67, 2011.

[11] G. Akman-Demir, P. Serdaroglu, and B. Tasci, "Clinical patterns of neurological involvement in Behçet's disease: evaluation of 200 patients," Brain, vol. 122, Part 11, pp. 2171-2182, 1999.

[12] R. Talarico, A. d'Ascanio, M. Figus et al., "Behçet's disease: features of neurological involvement in a dedicated centre in Italy," Clinical and Experimental Rheumatology, vol. 30, no. 3, Supplement 72, pp. S69-S72, 2012.

[13] International Study Group for Behcet's Disease, "Criteria for diagnosis of Behcet's disease," The Lancet, vol. 335, no. 8697, pp. 1078-1080, 1990.

[14] “The International Criteria for Behçet's Disease (ICBD): a collaborative study of 27 countries on the sensitivity and specificity of the new criteria," Journal of the European Academy of Dermatology and Venereology, vol. 28, no. 3, pp. 338-347, 2014.

[15] S. Kalra, A. Silman, G. Akman-Demir et al., "Diagnosis and management of Neuro-Behçet's disease: international consensus recommendations," Journal of Neurology, vol. 261, no. 9, pp. 1662-1676, 2014.

[16] J. L. Banks and C. A. Marotta, "Outcomes validity and reliability of the modified Rankin scale: implications for stroke clinical trials: a literature review and synthesis," Stroke, vol. 38, no. 3, pp. 1091-1096, 2007.

[17] A. Al-Araji, K. Sharquie, and Z. Al-Rawi, "Prevalence and patterns of neurological involvement in Behcet's disease: a prospective study from Iraq," Journal of Neurology, Neurosurgery \& Psychiatry, vol. 74, no. 5, pp. 608-613, 2003.

[18] C. Lafitte, J. Servan, J. M. Bleibel, B. Wechsler, and J. Y. Delattre, "Meningomyelitis disclosing Behçet's disease," Revue Neurologique, vol. 152, no. 3, pp. 205-207, 1996. 
[19] M. K. Sharief, R. Hentges, and E. Thomas, "Significance of CSF immunoglobulins in monitoring neurologic disease activity in Behcet's disease," Neurology, vol. 41, no. 9, pp. 1398-1401, 1991.

[20] G. Akman-Demir, E. Tüzün, S. İçöz et al., "Interleukin-6 in neuro-Behçet's disease: association with disease subsets and long-term outcome," Cytokine, vol. 44, no. 3, pp. 373-376, 2008.

[21] O. Coban, S. Bahar, G. Akman-Demir et al., "Masked assessment of MRI findings: is it possible to differentiate neuroBehçet's disease from other central nervous system diseases? [corrected]," Neuroradiology, vol. 41, no. 4, pp. 255-260, 1999.

[22] S. Hirohata, "Histopathology of central nervous system lesions in Behçet's disease," Journal of the Neurological Sciences, vol. 267, no. 1-2, pp. 41-47, 2008.

[23] S. Hirohata, H. Kikuchi, T. Sawada et al., "Clinical characteristics of neuro-Behcet's disease in Japan: a multicenter retrospective analysis," Modern Rheumatology, vol. 22, no. 3, pp. 405-413, 2012.

[24] Y. Ozguler, P. Leccese, R. Christensen et al., "Management of major organ involvement of Behçet's syndrome: a systematic review for update of the EULAR recommendations," Rheumatology, vol. 57, no. 12, pp. 2200-2212, 2018.

[25] G. Hatemi, R. Christensen, D. Bang et al., "2018 update of the EULAR recommendations for the management of Behçet's syndrome," Annals of the Rheumatic Diseases, vol. 77, no. 6, 2018.

[26] B. Zeydan, U. Uygunoglu, S. Saip et al., "Infliximab is a plausible alternative for neurologic complications of Behçet disease," Neurology - Neuroimmunology Neuroinflammation, vol. 3, no. 5, p. e258, 2016.

[27] O. Addimanda, N. Pipitone, G. Pazzola, and C. Salvarani, "Tocilizumab for severe refractory neuro-Behçet: three cases IL-6 blockade in neuro-Behçet," Seminars in Arthritis and Rheumatism, vol. 44, no. 4, pp. 472-475, 2015.

[28] G. Emmi, R. Talarico, G. Lopalco et al., "Efficacy and safety profile of anti-interleukin-1 treatment in Behçet's disease: a multicenter retrospective study," Clinical Rheumatology, vol. 35, no. 5, pp. 1281-1286, 2016. 


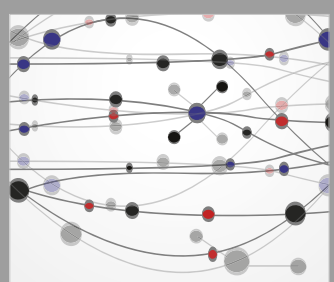

The Scientific World Journal
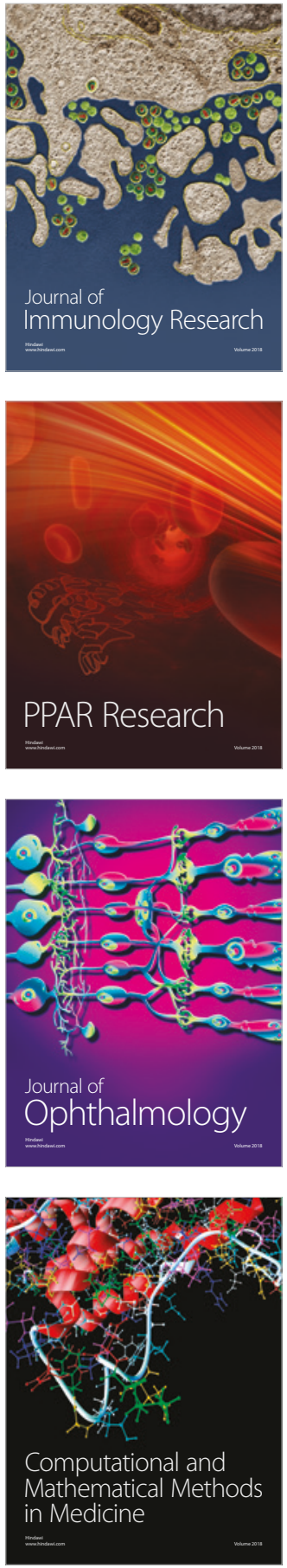

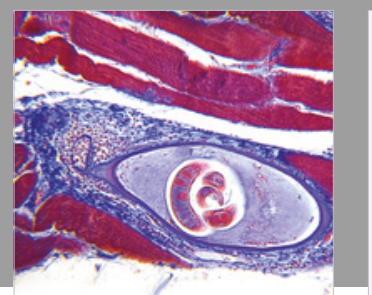

Gastroenterology Research and Practice

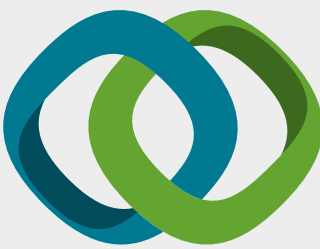

\section{Hindawi}

Submit your manuscripts at

www.hindawi.com
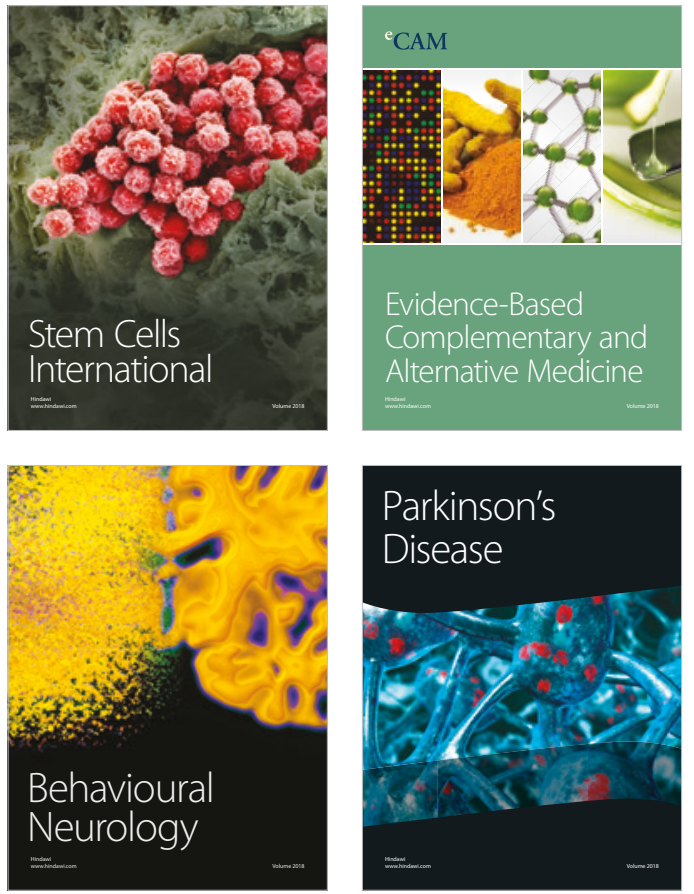

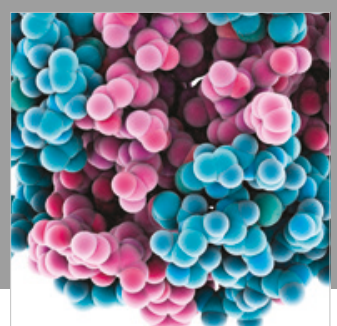

ournal of

Diabetes Research

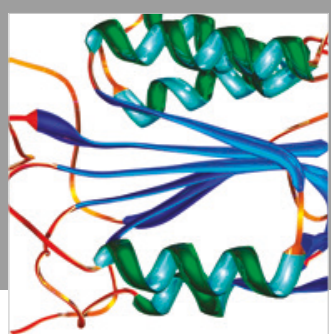

Disease Markers
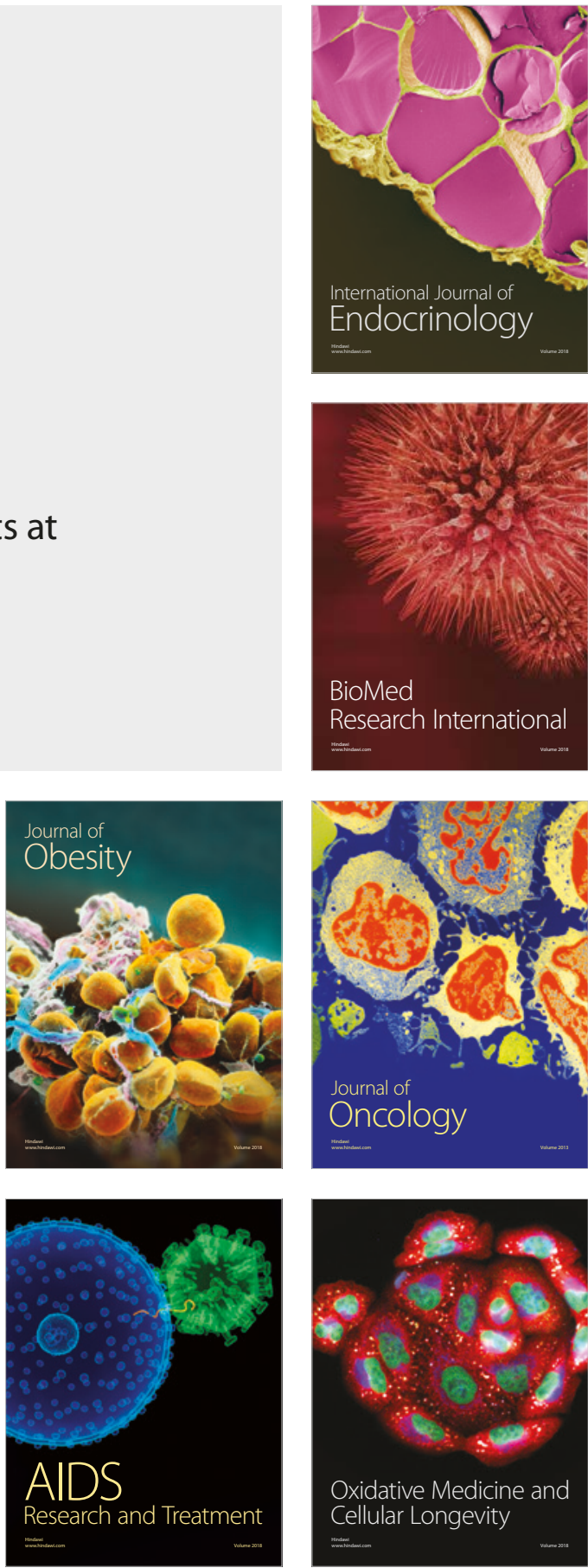